\title{
A Framework of User Classification Model of Online User Innovation Communities Based on User Innovation Value
}

\author{
Jingjing Yang \\ School of Management, Jinan University, Guangzhou, China \\ Email: jingjing_yang1994@163.com
}

How to cite this paper: Yang, J. J. (2020). A Framework of User Classification Model of Online User Innovation Communities Based on User Innovation Value. Open Journal of Social Sciences, 8, 232-244. https://doi.org/10.4236/jss.2020.85016

Received: May 5, 2020

Accepted: May 19, 2020

Published: May 22, 2020

Copyright $\odot 2020$ by author(s) and Scientific Research Publishing Inc. This work is licensed under the Creative Commons Attribution International License (CC BY 4.0).

http://creativecommons.org/licenses/by/4.0/

\section{(c) (i) Open Access}

\begin{abstract}
The online user innovation communities (OUICs) provide a platform for users to participate in innovation activities, share product experience, and interact with each other. Different types of users have different innovation values. Classification of users can facilitate better community management and maximize the value of users. In the existing user classification research, the analysis of user innovation value is not in-depth enough, and the professional knowledge of each stage of product development possessed by users is not fully considered, which is the key to maximize the value of user innovation. Therefore, we comprehensively consider the user's innovation capability, professional capability, influence capability and active capability, and propose a measurement method of user innovation value (4C). And based on user innovation value, a framework of a three-dimensional user classification model (TIS) was proposed combined with the product development stages and topics that users participated in, which contains topics, innovation value, and stage. It can enable companies to introduce high-innovation value users with different professional knowledge backgrounds at different stages of product development, and give full play to their innovation value, which is conducive to improving the product innovation performance of companies.
\end{abstract}

\section{Keywords}

User Innovation Value, User Classification Model, Online User Innovation Communities

\section{Introduction}

Users are one of the important sources of company innovation (Von Hippel, 1986). User innovation creates more competitive advantages in traditional mode 
(Raasch \& Von Hippel, 2012; Fuchs \& Schreier, 2011; Antorini \& Muñiz, 2013), which will inevitably change the traditional process of new product development (Mallapragada, Grewal, \& Lilien, 2012). User innovation is defined as the user's initiative to undertake the task of innovation. Especially in the stage of product creative thinking and concept prototype, users can often provide tremendous help and improve the speed of the two stages (Chang \& Taylor, 2016). With the rapid development of the Internet, it is often the user's "personalized needs" that are more easily expressed, which is convenient for companies to have real-time contact with customers to know their needs in a close distance. And OUICs are important platform for companies to communicate with users, and for users to express demands and exchange knowledge. Dell, Lego, Starbucks and other world-renowned companies have built open innovations by building OUICs, including users as an extremely important innovation subject into the company's innovation cooperation subject, and combining internal and external ideas for innovation (Ogink \& Dong, 2019). They use users' creative ideas, designs and feedback to promote the formation of new products, in order to improve the company's innovation performance.

Online user innovation communities have gradually become the main platform for customers to participate in product innovation online, and users' willingness to contribute innovative knowledge comes from their own motivations. The most typical motivation is the user's interest in related products and technologies, with the intention of obtaining higher value experience from the product improvement they participate in the design (Janzik \& Herstatt, 2008; Jeppesen \& Frederiksen, 2006; Parmentier \& Mangematin, 2014). For example, many users in the Xiaomi community are technical enthusiasts of smartphones or Xiaomi products. Users who have a high degree of recognition for the company will contribute their own value (de Vries, Boon, \& Peine, 2016). 23\% of the product improvement ideas put forward by users according to their own needs can realize the commercialized application value, which brings huge revenue for companies (de Jong \& Flowers, 2018). As communication platforms for continuous improvement and innovation of the product, the OUICs have a large number of users, but different users have different values for companies to carry out product innovation activities. Each user has different expertise and product use experience, which means that different users will participate in different topics when participating in community activities. At the same time, each user's participation in the community is based on different motives, such as improving the product and analyzing the product experience. This also destined that there are differences in the product development stage in which each user participates. The user's participation and interactive behavior will form a "community" in the community, the interaction between groups is more conducive to the formation and diffusion of innovative knowledge, but in addition to users who continue to bring innovative ideas to the community, there are also a large number of lurkers who bring little value to the community, so how to identify the group based 
on user innovation value, so as to provide guidance for enterprise innovation is very necessary. However, most of the existing researches focus on the identification of leading users from the perspective of $0-1$ or from the perspectives of user participation behavior (Füller et al., 2014; Barcellini, Détienne, \& Burkhard, 2014) and contribution (Guo et al., 2017), etc., without in-depth analysis of the user's innovative value. But the inevitable development trend of the current user classification is to realize the non-manual processing of user-generated content through natural language processing and big data technology, and based on multi-dimensional perspectives, such as product development stages and topics that users participate in, to better explore high value customers and realize the maximization of user innovation value, providing more innovative knowledge for company's product innovation.

Therefore, the fill the gap of previous research, this paper makes use of user participation and interactive behavior to examine the value of users to company innovation activities, and proposes a user innovation value measurement method (4C). Based on it, we propose a framework of a three-dimensional user classification model, TIS (Topic, innovation, stage), taking into account the topics and the product development stage that users participate in. Thus, the contributions of this article are as follows:

1) The user innovation value measurement method $4 \mathrm{C}$ is proposed. This method comprehensively considers the user's innovation capability, professional capability, influence capability and active capability which can identify the users with the most innovative value.

2) Based on the user innovation value, and combined with the theme and product development stage, the framework of a three-dimensional user group classification model is constructed to facilitate community managers to categorize users based on the three dimensions of user innovation value, knowledge professionalism, and product development stage, and to strengthen the incentives for community users, promoting community innovation activities.

\section{Literature Review}

\subsection{Lead Users}

Von Hippel (1986) believes that lead users should have two basic characteristics. One is that the demand of lead users is ahead of ordinary users; and the other is that lead users have a strong motivation for innovation. Traditional market researches focus on the target consumers and their needs in the target market. And they do not understand the lead users and do not care much about the existing solutions. But the lead users may already have developed solutions, while traditional market research has long since lost out on innovative product ideas from lead users. Compared with ordinary users, product innovation is very early for lead users, even earlier than the commercialization of the similar products. Professor Von Hippel (1986) distinguished lead users from ordinary users in order to emphasize the role of lead users in the early process of innovation. Through 
different forms of contact with lead users, you will find that they can stimulate various innovations thoughts.

Drawing on the work of Von Hippel (1986), researchers have expanded the characteristics of lead users. The main characteristics of lead users in relevant literatures are shown in Table 1.

Based on the characteristics of the lead users, the researchers carry out the identification of the leading users. Early research was conducted based on questionnaires and interviews. But with the development of the Internet and the emergence of OUICs, researchers have begun to use Internet technology to conduct research. For example, Pajo et al. (2015) proposed the FLUID (Fast Lead User Identification) framework based on data mining technology and used C4. 5 algorithm classifies users randomly selected from Twitter, founding that this method can achieve a recognition accuracy of 98\%. Later Pajo, Vandevenne and Duflou (2017) proposed another lead user identification method for online innovation community based on user dynamic feature extraction.

Table 1. Characteristics of lead users.

\begin{tabular}{|c|c|}
\hline Characteristics & Studies \\
\hline \multirow{2}{*}{$\begin{array}{l}\text { High expect returns from } \\
\text { requirements solutions }\end{array}$} & Morrison, Roberts, \& Midgley (2004) \\
\hline & Oosterloo (2010) \\
\hline \multirow{4}{*}{$\begin{array}{l}\text { Strong dissatisfaction } \\
\text { with the existing products }\end{array}$} & Lüthje \& Herstatt (2004) \\
\hline & Conradie et al. (2016) \\
\hline & Belz \& Baumbach (2010) \\
\hline & Pajo et al. (2013) \\
\hline \multirow{4}{*}{ Potential as a leader } & Belz \& Baumbach (2010) \\
\hline & Pajo et al. (2013) \\
\hline & Liu et al. (2019) \\
\hline & Zhang, Li, \& Yu (2019) \\
\hline \multirow{4}{*}{ Participation } & Lüthje \& Herstatt (2004) \\
\hline & Belz \& Baumbach (2010) \\
\hline & Pajo et al. (2013) \\
\hline & Liu et al. (2019) \\
\hline $\begin{array}{l}\text { Adopting new products } \\
\text { faster than ordinary users }\end{array}$ & Pajo et al. (2013) \\
\hline \multirow{2}{*}{ Extensive product knowledge } & Lüthje \& Herstatt (2004) \\
\hline & Belz \& Baumbach (2010) \\
\hline \multirow{4}{*}{ Rich experience in product use } & Lüthje \& Herstatt (2004) \\
\hline & Conradie et al. (2016) \\
\hline & Belz \& Baumbach (2010) \\
\hline & Pajo et al. (2013) \\
\hline
\end{tabular}


Current research on lead user identification generally assumes that the lead user follows the 0-1 distribution, that is, a user is not a leading user, then he is a non-lead user. Due to the existence of different types of users in the community (Benamar, Balagué, \& Ghassany, 2017), it is not enough to simply divide community users into lead users and non-lead users when studying the impact of active users. Different types of users may have different effects on the innovation behavior of other users, and also bring different contributions to the community.

\subsection{Multi-Dimensional User Classification}

The multi-dimensional segmentation of users can better manage users to achieve effective user evaluation, reasonable allocation of service resources and successful implementation of user strategy. Meantime it provides theoretical and methodological guidance for companies to fully obtain user value. Researchers classify users according to different user attributes, as shown in Table 2. There are two main categories.

Table 2. Research summary of user classification in OUICs.

\begin{tabular}{|c|c|c|c|}
\hline Studies & Division criteria & User roles & Methodology \\
\hline Füller et al. (2014) & \multirow{4}{*}{ Participation } & $\begin{array}{c}\text { Idea generator } \\
\text { Socializer } \\
\text { Efficient contributor } \\
\text { Master } \\
\text { Passive commentator } \\
\text { Passive idea generator }\end{array}$ & $\begin{array}{c}\text { Social network analysis } \\
\text { Clustering analysis }\end{array}$ \\
\hline $\begin{array}{l}\text { Barcellini, Détienne, } \\
\text { \& Burkhardt (2014) }\end{array}$ & & $\begin{array}{c}\text { Interactor } \\
\text { information provider } \\
\text { coordinator } \\
\text { encourager }\end{array}$ & Improved PEP model \\
\hline $\begin{array}{l}\text { Toral, Martínez-Torres, } \\
\text { \& Barrero (2010) }\end{array}$ & & $\begin{array}{l}\text { Peripheral user } \\
\text { formal user } \\
\text { core user }\end{array}$ & Social network analysis \\
\hline $\begin{array}{c}\text { Moritz, Redlich, } \\
\text { \& Wulfsberg (2018) }\end{array}$ & & $\begin{array}{c}\text { Lurkers, Quiets, Coys, Stars, } \\
\text { Movers, Shakers }\end{array}$ & $\begin{array}{c}\text { Social network analysis } \\
\text { Empirical analysis }\end{array}$ \\
\hline Zhao et al. (2010) & Contribution & $\begin{array}{l}\text { Peripheral participant } \\
\text { active contributor } \\
\text { core contributor }\end{array}$ & Empirical analysis \\
\hline Guo et al. (2017) & \multirow[t]{2}{*}{$\begin{array}{l}\text { Participation } \\
\text { Contribution }\end{array}$} & $\begin{array}{l}\text { Project leader } \\
\text { Generalist } \\
\text { Active designer } \\
\text { Communicator } \\
\text { Passive designer } \\
\text { Observer }\end{array}$ & $\begin{array}{c}\text { Social network analysis } \\
\text { Clustering analysis }\end{array}$ \\
\hline Zheng \& Shen (2013) & & $\begin{array}{l}\text { Active login } \\
\text { active participant } \\
\text { indirect contributor } \\
\text { direct contributor }\end{array}$ & Empirical analysis \\
\hline
\end{tabular}


One type of mainstream research is to classify users based on their participation behavior. Cui and $\mathrm{Wu}$ (2016) classified customer participation in innovation into information source, cooperative developer or independent innovator through different forms of customer participation in product innovation. By using SNA technology to analyze the interaction and cooperation between users in OUICs, Toral, Martínez-Torres and Barrero (2010) divided the user groups of this community into three categories: peripheral users, formal users and core users, according to the macro-structure analysis of the network, and studied separately the roles of these three user groups in the OSS project.

Another type of mainstream research is to classify users based on user contribution behavior or degree of user contribution. In their study of the open source software community, Hemetsberger and Pieters (2001) divided customers into three categories: main contributors, contributors and ordinary users on the basis of their different contributions in the process of participating in the development of new products. Füller et al. (2014) summarized the user roles of the innovation competition community into six categories: idea generator, socializer, efficient contributor, master, passive idea generator and passive commentator according to the differences in user's contribution behavior. And they further analyzed the differences in interaction content and contribution quality of these six categories of users.

It can be found that in the current research on the user classification of OUICs, whether it is the identification of lead users or multi-dimensional user classification, the innovation value of the user itself and the value created by the text information in the generated content are ignored, and less attention is paid to the product knowledge that users own and product development stage that users participate in. However, these aspects are the key for different users to exert their professional product knowledge in different product development stages to maximize their innovation value. Therefore, we make use of user participation and interactive behavior to examine the value of users to company innovation activities, and put forward a measurement method, 4C. And then, by taking into account the topics that users participate in and the product development stages involved, we propose a three-dimensional user classification model, TIS, based on innovation value measurement.

\section{Theoretical Framework Construction}

\subsection{User Innovation Value Measurement Method}

The innovation value of the user not only refers to the innovation capability of users, but also should comprehensively consider the professional capability, influence capability and active capability of users. The professional capability possessed by a user can reflect the user's reserve of product expertise. Only the user with high expertise in a certain range of knowledge or a wide range of knowledge can put forward valuable innovative ideas. The influence capability can reflect the popularity of a user in the community and the influence of the user on other users in the community. Users with high influence are generally well-known to most 
people, and have high leadership and appeal in the community. Active capability reflects the overall activity level of a user in the community. And active users can continuously inject vitality and contribute knowledge to the community. Drawing on the current research on user classification, this article focuses on user participation and interactive behavior, combining the four types of capabilities of users, and proposes a $4 \mathrm{C}$ measurement method for user innovation value (IV). The specific contents are as follows:

\subsubsection{Innovation Capability}

Innovation capability $\left(I_{n n} C\right)$ refers to the capability of a user to innovate actively in the online innovation community and gain recognition in this process. The greater the capability to innovate, the more innovative activities users perform in the community, and the more likely they will be recognized. It is measured from the perspective of innovation quantity and innovation quality.

1) Innovation quantity $\left(I_{n n} C_{N}\right)$. It refers to the number of innovative posts posted by a user. We can use keywords such as "suggestion", "addition", "improvement" and other words to determine whether it is an innovative post, and summarize innovative posts like these.

2) Innovation quality $\left(I_{n n} C_{Q}\right)$. That is, the degree of recognition, with the official label of posts, such as the number of elite posts $\left(X_{1}\right)$, which is shown as a red mark in Figure 1, a post from Xiaomi community, to measure the degree of recognition of managers, and with the average score $\left(X_{2}\right)$ to measure the degree of recognition of other users.

The measurement equation of $\mathrm{A}$ is as follows:

$$
I_{n n} C_{Q}=\alpha_{1} X_{1}+\alpha_{2} X_{2}
$$

where $\alpha_{1}$ and $\alpha_{2}$ respectively represent the weight of official recognition and user recognition.

Thus, Innovation capability $\left(I_{n n} C\right)$ is measured as follows:

$$
I_{n n} C=\beta_{1} I_{n n} C_{N}+\beta_{2} I_{n n} C_{Q}=\beta_{1} I_{n n} C_{N}+\beta_{2}\left(\alpha_{1} X_{1}+\alpha_{2} X_{2}\right)
$$

where $\beta_{1}$ and $\beta_{2}$ respectively represent the weight of official recognition and user recognition.

\subsubsection{Professional Capability}

Professional capability $(P C)$ refers to the ability of users to express their accumulated professional knowledge in community activities. When users participate in different topics of community activities, they can show their professional knowledge. This capability can be measured by the depth and breadth of knowledge that a user own.

1) Knowledge depth $\left(K_{D}\right)$. It means the degree of expertise and depth of the user's knowledge, which is reflected in the depth of the user's knowledge of a few products or topics. If the user participates in the interaction with certain categories of topics, the greater the depth of the product's vertical mining, that is, the greater the depth of knowledge. It can be measured by the average of each post's professionalism $\left(P_{P}\right)$. 


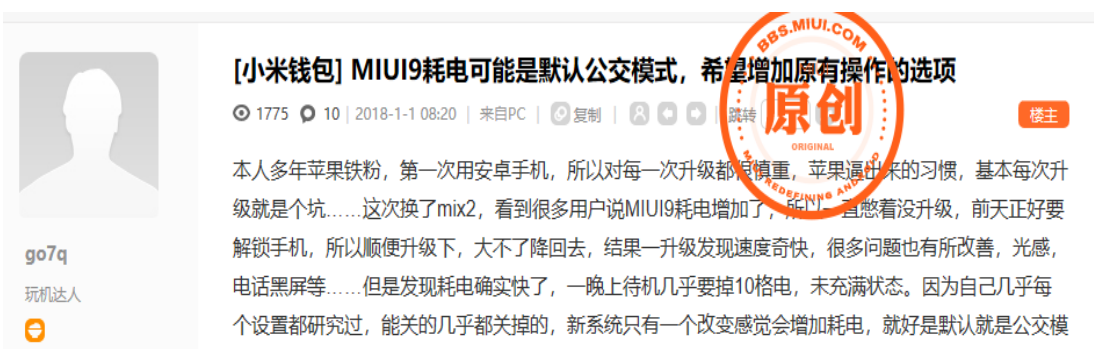

Figure 1. Official label of posts.

$$
K_{D}=A V G P_{P}=A V G\left(\frac{N_{K}}{N_{n}}\right)
$$

where $N_{K}$ is the number of professional words, and $N_{n}$ is the number of feature words after stopping words (i.e. the number of nouns).

2) Knowledge breadth $\left(K_{B}\right)$. Refers to the richness and diversification of knowledge reserved by users, which is reflected in the breadth of product knowledge and topics involved by users. If there are more product knowledge categories involved in user interaction, the wider the product knowledge, the greater the breadth of knowledge. It can be measured by the number of different topics that users participate in.

Thus, professional capability $(P C)$ is measured as follows:

$$
P C=\beta_{3} K_{D}+\beta_{4} K_{B}
$$

where $\beta_{3}$ and $\beta_{4}$ are the weights of knowledge depth and knowledge breadth respectively.

\subsubsection{Influence Capability}

Influence capability $\left(I_{n f l} C\right.$ ) is the influence degree of a user in interactive relationship network and social relationship network, which can reflect the position of users in interactive relationship network and social relationship network, and it can be measured by the betweenness centrality of interactive relationship network and the of social relationship network, which can be measured by using Gephi (an open-source network analysis and visualization software package).

1) Betweenness centrality of interactive relationship network $\left(I_{i b}\right)$. When a user participates in community interaction, he will form an interactive relationship network with other users. The betweenness centrality of interactive relationship network can explain the degree of user influence in the interactive relationship network.

2) Betweenness centrality of social relationship network $\left(I_{s b}\right)$. When a user establishes a direct social relationship with other users in the community, he will form an interactive relationship network with other users. The betweenness centrality of social relationship network can explain the degree of user influence among friends.

Thus, the measurement of influence capability $\left(I_{n f l} C\right)$ is as follows:

$$
I_{n f l} C=\beta_{5} I_{i b}+\beta_{6} I_{s b}
$$


where $\beta_{5}$ and $\beta_{6}$ are the weights of the betweenness centrality of interactive relationship network and the social relationship network respectively.

\subsubsection{Active Capability}

Active capability $(A C)$ is how active a user is in an online innovation community, as measured by the total number of posts, replies, and online duration. Only active users can keep the OUICs sustainable development.

$$
A C=\beta_{7} N_{P}+\beta_{8} N_{R}+\beta_{9} N_{D}
$$

where $N_{P}, N_{R}, N_{D}$ are the number of posts, replies, and online duration; $\beta_{7}, \beta_{8}, \beta_{9}$ are the weight respectively.

In summary, user innovation value measurement model, $4 \mathrm{C}$, is as follows:

$$
\begin{aligned}
I V= & \omega_{1} I_{n n} C+\omega_{2} P C+\omega_{3} I_{n f l} C+\omega_{4} A C \\
= & \omega_{1}\left(\beta_{1} C C_{N}+\beta_{2} C C_{Q}\right)+\omega_{2}\left(\beta_{3} K_{D}+\beta_{4} K_{B}\right) \\
& +\omega_{3}\left(\beta_{5} I_{i b}+\beta_{6} I_{s b}\right)+\omega_{4}\left(\beta_{5} I_{i b}+\beta_{6} I_{s b}\right) \\
= & \omega_{1}\left\{\beta_{1} C C_{N}+\beta_{2}\left(\alpha_{1} X_{1}+\alpha_{2} X_{2}\right)\right\}+\omega_{2}\left(\beta_{3} K_{D}+\beta_{4} K_{B}\right) \\
& +\omega_{3}\left(\beta_{5} I_{i b}+\beta_{6} I_{s b}\right)+\omega_{4}\left(\beta_{5} I_{i b}+\beta_{6} I_{s b}\right)
\end{aligned}
$$

where $\omega_{1}, \omega_{2}, \omega_{3}$ and $\omega_{4}$ are the weights of innovation capability, professional capability, influence capability and active capability respectively.

Finally, it should be stated that all variables can be obtained by using post information and user id data crawled by Python, and all the weight vectors $(\alpha, \beta, \omega)$ in the formula can be defined manually or determined by scientific methods such as analytic hierarchy process (AHP).

\subsection{User Classification Model}

To make full use of the innovation value of users in different stages of product development, in addition to understanding their innovation value, it is also necessary to understand the expertise that users are good at and the product development stage that they often participate in. Users to participate in community activities are based on the different experience and professional knowledge, use different participation motivation. So companies want to realize the full exploitation of users' product knowledge and their innovative value at different stages of product development, they must identify the product knowledge owned by users and the product development stage that they often participate in on the basis of the measurement of user innovation value, and classify users to maximize user value. Therefore, based on the user innovation value measurement model (4C) constructed above, this paper combines the two dimensions of user participation topics and product development stage to form a three-dimensional user classification model, TIS model.

Many researchers have divided the new product development activities that customers can participate in OUICs into several stages. For example, Kim et al. (2008) divided the innovation process of OUICs in which customers can participate in three main stages: idea generation, product development and testing, 
product listing and profit management. Füller et al. (2012) divided the open innovation process that customers can participate in into four main stages: generating ideas and problems, evaluating and selecting product concepts, experiencing and testing new products, and communicating product value to customer. On the basis of previous studies, this paper divides the product development stage of users' participating in into four stages: idea generation, design development, product testing and product experiencing.

When users participate in community activities, they will participate in different topics due to their different professional knowledge backgrounds. For example, some users are photography enthusiasts, so they give more feedback on camera function or pixel issues. Therefore, the dimension of professional knowledge is determined according to the topics and themes that each user participates in.

Based on the above analysis, the schematic diagram of the three-dimensional model (TIS) is shown in Figure 2. The method of cluster analysis can be used to realize the classification of users.

\section{Conclusion}

In this article, we propose the measurement method of innovation value (4C), which comprehensively considers the innovation capability, professional capability, influence capability and active capability possessed by users. The identified users with high innovation value not only have innovative ideas, but also rich professional knowledge. Therefore, the innovative ideas he put forward are based on their rich professional knowledge. At the same time, his high-influence capability and high-active capability show that his innovative ideas have certain representativeness and dissemination power. This method can expand the researchers' definition of innovative users.

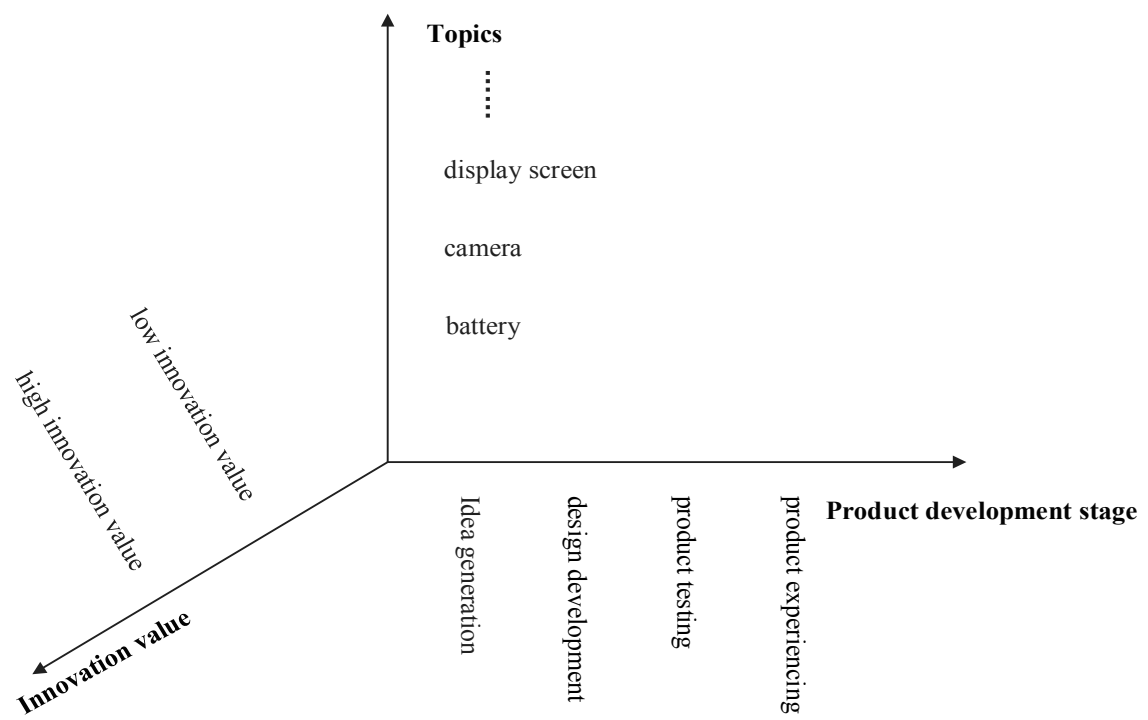

Figure 2. Schematic diagram of TIS model. 
The framework of user classification model (TIS model) we proposed provides theoretical guidance for user management in the online user innovation communities (OUICs), thereby improving the effective management and utilization of users in the community and maximizing the value of their innovation value. In the previous user classification model, the product development stages and topics that users participated in were not considered sufficiently. But the knowledge contributed by different users in different product development stages is different, because each user's knowledge stock and innovation value are differences. Through the TIS model proposed by us, companies can stimulate users with high innovation value to participate in product innovation and achieve joint innovation based on the product development stage that users often participate in, as well as their expertise in certain aspects. In this process, the TIS model can also realize the effective integration of resources, which can help companies to fully integrate the resources of users, which are external innovation subjects, to reduce the cost of product development. Meanwhile, the new developed products can also meet the needs of users and reduce the risk of product inconsistency with the market.

\section{Conflicts of Interest}

The author declares no conflicts of interest regarding the publication of this paper.

\section{References}

Antorini, Y. M., \& Muñiz, A. M. (2013). The Benefits and Challenges of Collaborating with User Communities. Research-Technology Management, 56, 21-28. https://doi.org/10.5437/08956308X5603931

Barcellini, F., Détienne, F., \& Burkhardt, J. M. (2014). A Situated Approach of Roles and Participation in Open Source Software Communities. Human-Computer Interaction, 29, 205-255. https://doi.org/10.1080/07370024.2013.812409

Belz, F. M., \& Baumbach, W. (2010). Netnography as a Method of Lead User Identification. Creativity and Innovation Management, 19, 304-313. https://doi.org/10.1111/j.1467-8691.2010.00571.x

Benamar, L., Balagué, C., \& Ghassany, M. (2017). The Identification and Influence of Social Roles in a Social Media Product Community. Journal of Computer-Mediated Communication, 22, 337-362. https://doi.org/10.1111/jcc4.12195

Chang, W., \& Taylor, S. A. (2016). The Effectiveness of Customer Participation in New Product Development: A Meta-Analysis. Journal of Marketing, 80, 47-64. https://doi.org/10.1509/jm.14.0057

Conradie, P. D., Herregodts, A. L., De Marez, L., \& Saldien, J. (2016). Product Ideation by Persons with Disabilities: An Analysis of Lead User Characteristics. In Proceedings of the 7th International Conference on Software Development and Technologies for Enhancing Accessibility and Fighting Info-Exclusion (pp. 69-76). Vila Real: ACM. https://doi.org/10.1145/3019943.3019954

Cui, A. S., \& Wu, F. (2016). Utilizing Customer Knowledge in Innovation: Antecedents and Impact of Customer Involvement on New Product Performance. Journal of the Academy of Marketing Science, 44, 516-538. 
https://doi.org/10.1007/s11747-015-0433-x

de Jong, J. P., \& Flowers, S. (2018). Free in, Free out? Outbound Transfer of User Innovations in Small UK Firms. Industrial Marketing Management, 73, 21-30.

https://doi.org/10.1016/j.indmarman.2018.01.008

de Vries, G. W., Boon, W. P., \& Peine, A. (2016). User-Led Innovation in Civic Energy Communities. Environmental Innovation and Societal Transitions, 19, 51-65. https://doi.org/10.1016/j.eist.2015.09.001

Fuchs, C., \& Schreier, M. (2011). Customer Empowerment in New Product Development. Journal of Product Innovation Management, 28, 17-32.

https://doi.org/10.1111/j.1540-5885.2010.00778.x

Füller, J., Hutter, K., Hautz, J., \& Matzler, K. (2014). User Roles and Contributions in Innovation-Contest Communities. Journal of Management Information Systems, 31, 273-308. https://doi.org/10.2753/MIS0742-1222310111

Füller, J., Matzler, K., Hutter, K., \& Hautz, J. (2012). Consumers' Creative Talent: Which Characteristics Qualify Consumers for Open Innovation Projects? An Exploration of Asymmetrical Effects. Creativity and Innovation Management, 21, 247-262. https://doi.org/10.1111/j.1467-8691.2012.00650.x

Guo, W., Zheng, Q., An, W., \& Peng, W. (2017). User Roles and Contributions during the New Product Development Process in Collaborative Innovation Communities. Applied Ergonomics, 63, 106-114. https://doi.org/10.1016/j.apergo.2017.04.013

Hemetsberger, A., \& Pieters, R. (2001). When Consumers Produce on the Internet: An Inquiry into Motivational Sources of Contribution to Joint-Innovation. In C. Derbaix et al. (Eds.), Proceedings of the Fourth International Research Seminar on Marketing Communications and Consumer Behavior (pp. 274-291). Puyricard: Institutd'Administration des Entreprsiesd'Aix-en-Provence, Universitéd'Aix-Marseille.

Janzik, L., \& Herstatt, C. (2008). Innovation Communities: Motivation and Incentives for Community Members to Contribute. In 2008 4th IEEE International Conference on Management of Innovation and Technology (pp. 350-355). Bangkok: IEEE.

https://doi.org/10.1109/ICMIT.2008.4654389

Jeppesen, L. B., \& Frederiksen, L. (2006). Why Do Users Contribute to Firm-Hosted User Communities? The Case of Computer-Controlled Music Instruments. Organization Science, 17, 45-63. https://doi.org/10.1287/orsc.1050.0156

Kim, J. H., Bae, Z. T., \& Kang, S. H. (2008). The Role of Online Brand Community in New Product Development: Case Studies on Digital Product Manufacturers in Korea. International Journal of Innovation Management, 12, 357-376. https://doi.org/10.1142/S1363919608002011

Liu, J., Zhang, Z., Qi, J., Wu, H., \& Chen, M. (2019). Understanding the Impact of Opinion Leaders' Characteristics on Online Group Knowledge-Sharing Engagement from In-Group and Out-Group Perspectives: Evidence from a Chinese Online Knowledge-Sharing Community. Sustainability, 11, 4461.

https://doi.org/10.3390/su11164461

Lüthje, C., \& Herstatt, C. (2004). The Lead User Method: An Outline of Empirical Findings and Issues for Future Research. R\&D Management, 34, 553-568. https://doi.org/10.1111/j.1467-9310.2004.00362.x

Mallapragada, G., Grewal, R., \& Lilien, G. (2012). User-Generated Open Source Products: Founder's Social Capital and Time to Product Release. Marketing Science, 31, 474-492. https://doi.org/10.1287/mksc. 1110.0690

Moritz, M., Redlich, T., \& Wulfsberg, J. (2018). Who Are Your Design Heroes? Exploring User Roles in a Co-Creation Community. In World Conference on Information Sys- 
tems and Technologies (pp. 399-410). Cham: Springer.

https://doi.org/10.1007/978-3-319-77703-0_40

Morrison, P. D., Roberts, J. H., \& Midgley, D. F. (2004). The Nature of Lead Users and Measurement of Leading Edge Status. Research Policy, 33, 351-362. https://doi.org/10.1016/j.respol.2003.09.007

Ogink, T., \& Dong, J. Q. (2019). Stimulating Innovation by User Feedback on Social Media: The Case of an Online User Innovation Community. Technological Forecasting and Social Change, 144, 295-302. https://doi.org/10.1016/j.techfore.2017.07.029

Oosterloo, A. (2010). Organizations as Professional Communities in the Post-Modern Era. Bulletin of the Transilvania University of Braşov, 3, 52.

Pajo, S., Vandevenne, D., \& Duflou, J. R. (2017). Automated Feature Extraction from Social Media for Systematic Lead User Identification. Technology Analysis \& Strategic Management, 29, 642-654. https://doi.org/10.1080/09537325.2016.1220517

Pajo, S., Verhaegen, P. A., Vandevenne, D., \& Duflou, J. R. (2013). Analysis of Automatic Online Lead User Identification. In Smart Product Engineering (pp. 505-514). Berlin, Heidelberg: Springer. https://doi.org/10.1007/978-3-642-30817-8_49

Pajo, S., Verhaegen, P. A., Vandevenne, D., \& Duflou, J. R. (2015). Fast Lead User Identification Framework. Procedia Engineering, 131, 1140-1145.

https://doi.org/10.1016/j.proeng.2015.12.434

Parmentier, G., \& Mangematin, V. (2014). Orchestrating Innovation with User Communities in the Creative Industries. Technological Forecasting and Social Change, 83, 40-53. https://doi.org/10.1016/j.techfore.2013.03.007

Raasch, C., \& Von Hippel, E. (2012). Modeling Interactions between User and Producer Innovation: User-Contested and User-Complemented Markets. SSRN Elibrary (June 7, 2012). https://doi.org/10.2139/ssrn.2079763

Toral, S. L., Martínez-Torres, M. D. R., \& Barrero, F. (2010). Analysis of Virtual Communities Supporting OSS Projects Using Social Network Analysis. Information and Software Technology, 52, 296-303. https://doi.org/10.1016/j.infsof.2009.10.007

Von Hippel, E. (1986). Lead Users: A Source of Novel Product Concepts. Management Science, 32, 791-805. https://doi.org/10.1287/mnsc.32.7.791

Zhang, F., Li, S., \& Yu, Z. (2019). The Super User Selection for Building a Sustainable Online Social Network Marketing Community. Multimedia Tools and Applications, 78, 14777-14798. https://doi.org/10.1007/s11042-018-6829-0

Zhao, Y., Wu, K., Zhu, Q., \& Meng, F. (2010). Exploring User's Classification Model for UGC and Its Influence Factors on Contribution in Social Media. In Proceedings of the 1st International Conference on E-Business Intelligence. Oxford: Atlantis Press. https://doi.org/10.2991/icebi.2010.52

Zheng, Z., \& Shen, L. (2013). The Formation of Consumer's Role in Virtual Communities. In 2013 Sixth International Symposium on Computational Intelligence and Design (Vol. 2, pp. 189-192). Hangzhou: IEEE. https://doi.org/10.1109/ISCID.2013.161 